We thank $\mathrm{Mr}$ Tim Marshall and Dr Keith Williams, department of social medicine, University of Birmingham for advice on statistics.

Bancroft J, Skrimshire A, Casson J, Harvard-Watts (), Revnolds F. P'ople who deliberately poison or injure themselves: their problems and their contact with helping agencies. P'swchol Med 1977:7:289-303.

2 Hawton K., Goldacre M. Hospital admissions for adverse effects of medicina! agents mainly self poisonings among adolescents in the ()xford region. Br7Psychiatr 1982:141:166-70.

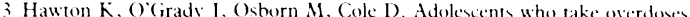

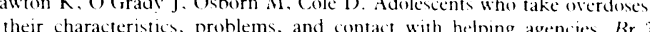
their characterintis, prohlens.

+ Bancrott J, Marsack P. The repetitiveness of self peisening and self injury Br7 Psychutr. 1977:131:394-9.

Aciepted 3 Famuary 1990

\title{
Orbital pseudotumour secondary to giant cell arteritis: an unreported condition
}

\section{A H Laidlaw, P E M Smith, P Hudgson}

Bristol Eye Hospital, Bristol BS1 2LX

D A H Laidlaw, senior house officer in ophthalmology

Newcastle General Hospital, Newcastle upon Tyne NE4 6BE

P E M Smith, registrar in neurology

P Hudgson, consultant

neurologist

Correspondence to:

Dr Laidlaw.

Br.Med f 1990;300:78-
Giant cell arteritis causes sudden blindness but may also cause ophthalmoparesis, attributable to infarction of the cranial nerve or extraocular muscle. Orbital pseudotumour associated with painful diplopia has been recognised in other types of vasculitis but not previously in giant cell arteritis.

\section{Case report}

A 66 year old woman gave a 10 day history of malaise, fever, aches in the head and eye, pain in the cheeks worsened by chewing, and tender lumps on her temples. Sinusitis had been diagnosed, and she had been treated with oral co-trimoxazole, amoxycillin and clavulanic acid, and ciprofloxacin for seven days, and with intravenous amoxycillin and clavulanic acid for one day, with no relief. For two days she experienced diplopia and noticed prominence of her right eye. When examined she had a fever $\left(37 \cdot 5^{\circ} \mathrm{C}\right)$ and dilated, pulsatile, non-tender temporal and occipital arteries. There was $4 \mathrm{~mm}$ right sided proptosis, measured with an exophthalmometer, and globally restricted right eye movements; there was no ptosis, abnormality of the pupils or optic discs, loss of visual acuity, or sensory loss. The erythrocyte sedimentation rate (Westergren method) was $122 \mathrm{~mm}$ in the first hour and her white cell count was normal, but aspartate transaminase and alkaline phosphatase activities were moderately raised. Examination of the cerebrospinal fluid showed a lymphocyte count of $7 \times 10^{6} / 1$. Computed tomography of the orbits confirmed proptosis of the right globe with normal extraocular muscles and paranasal sinuses. A temporal artery biopsy subsequently confirmed the diagnosis of giant cell arteritis.

She was treated with oral prednisolone $80 \mathrm{mg}$ daily. Within six hours her headache improved and within 36 hours she no longer had fever or diplopia and the proptosis had resolved. After 10 days the erythrocyte sedimentation rate and liver enzyme activity were normal. She was well four months after presenting, taking gradually reduced doses of steroids.

\section{Comment}

Patients with giant cell arteritis have occasionally experienced diplopia and presented with extraocular muscle paresis. ${ }^{\prime}$ This is often attributable to infarction of the cranial nerve trunk,' although ischaemic necrosis of the extraocular muscle has also been shown. ${ }^{2}$ Perivascular oedema accompanying vasculitic conditions such as polyarteritis nodosa ${ }^{3}$ and Wegener's granulomatosis ${ }^{4}$ can lead to varying degrees of inflammation of the orbital soft tissue. When this affects extraocular muscle (orbital myositis) painful diplopia may occur; more extensive diffuse or discrete orbital inflammation (orbital pseudotumour) with painful proptosis and ophthalmoparesis has also been seen. Although orbital pseudotumour has not been described previously in patients with giant cell arteritis, its occurrence was predicted in a recent review. ${ }^{5}$ Giant cell arteritis was confirmed histologically in our case, and the prompt resolution of painful proptosis induced by steroid treatment supports the diagnosis of orbital pseudotumour associated with vasculitis causing globally restricted eye movements. It was unlikely that our patient had an infection of the orbit as no organism or source was identified, and she responded rapidly to steroids but not to broad spectrum antibiotics.

Recognising that giant cell arteritis may cause painful orbital pseudotumour may prevent a delay in diagnosis and reduce the threat to vision.

We thank Mrs A Bowe for typing the manuscript.

1 Meadows SP. Temporal or giant cell arteritis. Proceedings of Roval Society of Medicine 1966:59:329-33.

2 Barricks ME, Traviesa DB, Glaser JS, Levy IS. Ophthalmoplegia and cranial arteritis. Brain 1977;100:209-21.

3 Jakobiec FA, Jones IS. Orbital inflammation. In: Duane TD, ed. Clinical ophthalmology. Vol 2. Philadelphia: Harper and Row, 1987:1-35.

4 Faulds J, Wear A. Pseudotumour of the orbit and Wegener's granulomatosis. Lancet 1960;ii:955-7.

5 Miller NR. Inflammatory myopathies. In: Miller NR, ed. Walsh and Hoyt's clinical neuro-ophthalmology. 4th ed. Vol 2. Baltimore: Williams and Wilkins, 1985:826-30.

(Accepted 29 December 1989
Northwick Park Hospital, Harrow, Middlesex HA1 3UJ

Huw G David, FRCS, registrar

Lawrence $S$ Freedman,

FRCS, consultant

Correspondence to: Mr David.

Br.Med 7 1990; 300:784-5

\section{Huw G David, Lawrence S Freedman}

Injuries sustained by people tripping over uneven or broken paving stones are not uncommon, though the incidence and severity of such injuries have not been recorded. We studied the number and type of such injuries recorded by our hospital.

\section{Department of \\ Orthopaedic Surgery, \\ Injuries caused by tripping over paving stones: an unappreciated problem}

\section{Patients, methods, and results}

Cases were collected retrospectively by analysis of the medicolegal reports prepared in our department during the 12 months January to December 1988. In addition, we included those patients seen prospectively in the fracture clinic during the three months January to March 1989. Only patients whose injuries had been directly caused by tripping over uneven, broken, or loose paving stones were included.

We found 27 fractures in 24 patients and one case of anterior dislocation of the shoulder. The table gives details of the injuries. Internal fixation was required in four cases. The other patients were treated conservatively, though six required manipulation of their 


\begin{tabular}{lr}
\hline Fractures of arm: & \\
Humerus & 2 \\
Acromion & 1 \\
Olecranon & 2 \\
Wrist & 9 \\
$\quad$ Distal radius & $8^{\star}$ \\
$\quad$ Scaphoid & 1 \\
Hand & 2 \\
$\quad$ Proximal phalanx of & \\
$\quad$ thumb & 1 \\
$\quad$ Fifth metacarpal & 1 \\
Fractures of leg: & \\
Pelvis (inferior pubic & \\
$\quad$ ramus) & 1 \\
Hip & 1 \\
Patella & 2 \\
Ankle & 3 \\
Foot (all fifth metacarpal) & 3 \\
Other injuries: & \\
Fracture of C1 arch & 1 \\
Shoulder dislocation & 1 \\
\hline
\end{tabular}

^One bilateral. fracture before immobilisation. The two most serious injuries were a fracture dislocation of the hip in a young man, which required open reduction and internal fixation, and a fracture of an arch of the atlas in an elderly woman.

\section{Comment}

Over 10000 claims for compensation for injuries sustained as a direct result of tripping over broken, uneven, or loose paving stones were made against local authorities in England and Wales in 1987, and this figure seems to be rising (A Walker, Municipal Mutual Insurance Company, personal communication). The number of patients seen in fracture clinics, however, suggests that far more people injure themselves on pavements than make a claim. Although less than $40 \%$ of claims for such injuries are successful, payments exceeded $110 \mathrm{~m}$ in England and Wales in 1987 alone. Indeed, insurance companies that are responsible for meeting settlements reached by the courts insist on regular inspections of pavements to ensure that such hazards are quickly rectified (A Walker, personal communication). Claims against local authorities are likely to be successful if the injury was caused by loose or rocking paving stones or if there was a difference in height of $15 \mathrm{~mm}$ or more between the stones (A Walker, personal communication).

Injuries caused by paving stones are not uncommon: over 150 patients are referred to the fracture clinics of this hospital each year for such injuries. In addition, numerous patients sustain soft tissue injuries and are not referred. The nature of the fractures incurred varies; patients often require admission to hospital, and the injury is occasionally serious. The cost to local authorities and ultimately rate payers in compensation is considerable and seems to be rising, yet our pavements do not seem to be getting any safer. Doctors and the general public alike need to be aware of the considerable risk of injury associated with the poor state of pavements, and local authorities must ensure that resources are made available for maintaining footpaths.

(Accepted 29 December 1989)

\section{Resuscitation decisions in a general hospital}

\author{
Kevin Stewart, Kathryn Abel, G S Rai
}

Department of Geriatric Medicine, Whittington Hospital, London N19 5NF Kevin Stewart, MRCP, senior registrar

Kathryn Abel, MA, senior house officer

G S Rai, FRCP, consultant physician

Correspondence to: Dr K Stewart, Department of Geriatric Medicine,

Middlesex Hospital, London WC1.

BrMed f 1990;300:785

Principal diagnosis for patients whose medical or nursing notes, or both, stated "do not resuscitate"

\begin{tabular}{lc}
\hline & $\begin{array}{c}\text { No of } \\
\text { patients }\end{array}$ \\
\hline Cerebrovascular accident & 19 \\
Malignancy & 9 \\
Cardiorespiratory disease & 9 \\
Dementia & 6 \\
Sepsis & 5 \\
Other & 9 \\
\hline Total & 57
\end{tabular}

Not all hospital inpatients are suitable for cardiopulmonary resuscitation. In the United States formalised "Do not resuscitate" policies exist, and in the United Kingdom most doctors now accept the need to make and document decisions about whether patients should be resuscitated.' Although there are many American reports on this subject, little has been published on what happens in British hospitals. ${ }^{2}$ We reviewed this hospital's procedure with regard to decisions not to resuscitate.

\section{Methods and results}

We reviewed the medical and nursing notes of all inpatients in the nine medical wards ( 221 beds) of this hospital on 31 March 1989. The hospital's established practice is for the medical team to consider the resuscitation state of each patient on admission and after each ward round and to document any decision not to resuscitate in the medical and nursing notes. Patients are admitted to the same wards under the care of general physicians or geriatricians. For each patient we recorded age, sex, diagnosis, and consultant and whether he or she should be resuscitated.

There were 178 inpatients (96 men) aged 17-95 (mean 61.5 years). A decision not to resuscitate had been made for 57 patients (table): the decision had been documented in both the medical and nursing notes in 26 cases, in the nursing notes alone in 28 , and in the medical notes alone in three. The reason for the decision was given in only four cases. Of those patients aged 75 and over, 13 out of 33 under general physicians had "do not resuscitate" in their notes compared with 21 out of 33 under geriatricians.

We identified a further 15 patients from the case notes whom we thought should probably not be resuscitated: seven with metastatic or untreatable malignancy and eight with moderate or severe functional impairment after stroke. Some of them had been inpatients for over six months without showing much improvement. There was no evidence that a decision had been made on whether these patients should be resuscitated.

\section{Comment}

The decision not to resuscitate had been made for $31 \%$ of the patients we studied. Assuming that cardiopulmonary resuscitation should be restricted to those most likely to benefit, a relatively high proportion of patients designated not for resuscitation is appropriate in general wards.

In many cases the decision had not been properly documented, and this could lead to inappropriate attempts at resuscitation. Although documentation of the reason behind a decision not to resuscitate is not necessarily required, we are disappointed to find it in only four cases. We believe that knowledge of the reason would improve the staff's understanding of the decision on resuscitation and help in audit of the decision making process.

We are concerned that we identified a fairly large number of patients whom we thought should not be resuscitated but had not been designated as such. This may have been because a decision not to resuscitate had been overlooked or not considered by the medical team or because the medical team did not want to make a decision at that time. Not making a decision about resuscitation, however, is equivalent to a decision to resuscitate. The problem might be overcome if resuscitation protocols required a definite decision for or against resuscitation to be made. We think that an ideal protocol should include a definite decision for or against resuscitation, a regular review of the decision, the reason behind the decision, and any implications the decision may have for other care. There should also be discussion and consultation with patients, their relatives, and other staff when making this decision. We are at present evaluating such a policy.

1 Bayliss RIS. Thou shalt not strive officiously. Br Med f 1982;285:1373-5. 2 Keating RM. Exclusion from resuscitation. F $R$ Soc Med 1989;82:402-5. 3 Hershey $\mathrm{CO}$, Fisher $\mathrm{L}$. Why outcome of resuscitation on general wards is poor. Lancet 1982;i:31-4

(Accepted 17 Norember 1989) 